\title{
EFFECTS OF PHYSICAL TRAINING AND BEHAVIOURAL STRATEGIES TOWARDS MUSCLE STRENGTH AND MENTAL HEALTH IN THE ELDERLY
}

\author{
AZLIYANA AZIZAN ${ }^{*}$, SHAZANA SAHRANI ${ }^{2}$, ASILAH ANUM ${ }^{1}$, \\ NURUL HUSNA $^{1}$ and FARID RAHMAN ${ }^{3}$ \\ ${ }^{I}$ Centre of Physiotherapy, Faculty of Health Sciences, \\ Universiti Teknologi MARA, Puncak Alam, 42300 Selangor, Malaysia \\ ${ }^{2}$ Family Health Development Division, Ministry of Health, Putrajaya, 62590 Putrajaya, Malaysia \\ ${ }^{3}$ Department of Physiotherapy, Faculty of Health Science, Universitas Muhammadiyah Surakarta, \\ Jalan A. Yani Pabelan, Kartasura 57162, Indonesia \\ *E-mail: azliyana9338@uitm.edu.my
}

Accepted 21 October 2021, Published online 30 November 2021

\begin{abstract}
The promotion of physical training (PT) and positive behavior in the elderly requires effective interventions. This study shows the effect of PT during an 11-week intervention program by applying behavioral strategies. A total of 63 participants aged 65 years old were randomly divided into three groups: Physical with a behavioral group, PB ( $n=18)$, Physical group, PG $(n=23)$, and Control group, CG $(n=22)$. PB and PG participants underwent a six-week group-based multi-component PT for one hour per session, three sessions a week. After PT, participants in PB began five-week behavioral exercises for $30 \mathrm{~min}$, twice a week. Meanwhile, CG participants only have to maintain their daily routines. Upper and lower limb muscle strength and mental health were assessed. Results from repeated measures ANOVA showed significant differences between groups due to time factor, group and time interaction, and between-group factor $(p<0.05)$ for Right UL, Left UL, and LL strength. Analysis of covariance (ANCOVA) for mental health $[\mathrm{F}(2.58)=33.49](p<0.05)]$ showed significant main effects among participants in PB, thus indicating improved mental health. In conclusion, combined of PT and behavioral strategies may be a promising strategy in enhancing better physical and mental well-being of the elderly.
\end{abstract}

Key words: Behavioural, elderly, mental health, physical

\section{INTRODUCTION}

The world's elderly continues to grow at an unprecedented rate. In Malaysia, the population aged 60 years and above has increased from $10.3 \%$ in 2019 to $10.7 \%$ in 2020 (Department of Statistics Malaysia, 2020). By the year 2030, Malaysia is estimated to be an aging country, with $15 \%$ of the elderly population (Saharani et al., 2016). As the aging population is increasing every year, extra care needs to be paid to the elderly to ensure their wellbeing at an optimal stage. (Ramely et al., 2017). Physical inactivity levels are rising in developing countries, and Malaysia is no exception (Guthold et al., 2008; Bauman et al., 2009). A previous study by Sazlina, Browning, and Yasin (2012) reported that the level of physical activity is low, and most of the

\footnotetext{
* To whom correspondence should be addressed.
}

Malay older persons are sedentary. This may suggest that an intervention is needed, especially for older persons living in Malaysia, to continue engaging in physical activity and seeking healthy lifestyles.

In aging, humans are slowly and steadily losing skeletal muscles that are primarily replaced by adipose and fibrous tissues (Mobasheri, 2012). A decline in muscle strength, slowing down muscle reflexes, and a lack of flexibility are the corresponding losses (Ketcham \& Stelmach, 2004). Research has claimed that muscle mass and strength are mainly related to a decline in skeletal muscle mitochondria (Peterson et al., 2012). In 2012, Peterson and his colleagues discovered that mitochondria were altered by several mechanisms, including increased mitochondrial DNA mutations, decreased mitochondrial activity, lower respiratory function, and possibly apoptosis. In the elderly, this 
leads to progressive muscle loss which resulted in sarcopenia and dynapenia.

Physical activity in the elderly may further be restricted due to overall deterioration in muscle function, which made them prone to risky incidence such as falls. Hence, it is important to have adequate skeletal muscle strength for better physical functioning and low muscle strength is a predictor of physical limitation in the elderly (Wilson et al., 2011). As seen in positive ways, the correlation of muscle function and age might be managed by controlling the involvement of individual physical activities despite their aging process.

As the most common mental disorder, depression did seriously affect the elderly, especially those who have other general conditions of comorbidities (Alcalá et al., 2007). In 2011, Mukhtar and Oei found that the total prevalence of depression in Malaysia was from $29 \%$ to $46 \%$. It was reported that community-dwelling elder was suffering from major depressive, mild depression, and clinically related depressive syndrome with a prevalence of $1.8 \%, 9.8 \%$, and $13.5 \%$ respectively (Beekman et al., 1999).

Condition of depression might be associated with cognitive deterioration and dementia. However, the exact causes of depression pathology are still not understood (Beekman et al., 1999). Most experiments have found that brain modifications are the leading cause of depression which is related to changes in the levels of dopamine, norepinephrine, and serotonin (Ballmaier et al., 2004; Smith, 2008; Tsopelas et al., 2011). These chemicals can affect mood and impulse in a person.

A psychiatric depression may be identified by a group of symptoms lasting for more than two weeks, including feelings of unbearable sadness and loss of enjoyment, such as sleep disruption, lack of energy, lack of focus, feelings of insignificance, and thoughts of suicide (Fitzgerald et al., 2008). Elderly with depression are less likely to resolve the disorder and result in a poor state of health (Donaghy, 2007; Majdi et al., 2011). Thus, this group of the population may trigger a worsening disease progression and changes in physical and psychological functions. In exchange, they may have an impact on their health-related social functions (HRQOL) (Wada et al., 2005; Majdi et al., 2011; Salguero, Martínez-García, Molinero \& Márquez, 2011). Previously the effect towards physical activities and behavioral components might become one of the challenging variables as it involves belief and different perceptions, thus results are inconclusive. Therefore, this current study aims to determine the effects of combined physical training and behavioral strategies towards muscle strength and mental health in the elderly.

\section{MATERIALS AND METHODS}

\section{Participants}

A controlled quasi-experimental analysis was carried out over an 11-week duration. Ninety elderly people over 60 years of age have been recruited from three separate villages around Selangor in Malaysia. Only one form of intervention was assigned to each village to prevent communications between the participants (Village $1=\mathrm{PB}$; Village $2=\mathrm{PG}$; Village $3=\mathrm{CG}$ ). Until the intervention was implemented, eligibility was screened for all participants. Participants were included based on the following criteria: (1) aged 60 and above, (2) no cognitive impairments $(<24$ were excluded for MMSE score), (3) active in daily life activities, (4) English or Malay comprehensible and (5) residing in the study setting. Participants who had chronic musculoskeletal issues, dementia or neurologic conditions, significant auditory disability, visual impairment, and unable to walk were removed from this research. This research included 73 elderly $(\mathrm{PB}=25, \mathrm{PG}=25$ and $\mathrm{CG}=23$ ) who met the inclusion criteria. At the end of the study, 18 in PB, 23 in PG, and 22 in CG dropped out in the study. Common explanations given by the dropout participants were transportation problems, time limitations, and bad weather.

\section{Exercise and Behavioural Protocol}

The PB has received a six-week training program with increasing frequency and intensity adapted from a previous study Azliyana and Maria (2016). The exercise program finished with another five weeks of a behavioral program. For six weeks the $\mathrm{PG}$ received the same protocol as in the PB group, but without the behavioral program. In contrast, no intervention but instructions were given to the control group (CG) to continue its regular activities. The measurements were taken at baseline, $12^{\text {th }}$ and $24^{\text {th }}$ weeks. The University Ethics Committee accepted the procedure for this study. Each participant was guaranteed confidentiality and an option to withdraw without penalty at any time.

\section{Measurements of muscle strength and mental health}

The primary outcome of this research was muscle strength and mental health. The arm curl test was used in this study to measure the upper limb strength, which was the ability of the arm to lift a 5-lb dumbbell for women and an 8-1b dumbbell for males (Milanović et al., 2013). The number of repetitions in $30 \mathrm{sec}$ was recorded using a stopwatch. While, for the lower limb strength, the chair rise test was used (Milanović et al., 2013). In this test, the number of repetitions performed (sit to stand) in 30 sec was measured. While for mental health, the 15items Geriatrics Depression Scales were used to 
obtain the level of depression among the elderly (Kørner et al., 2006). According to Nyunt et al. (2009) the GDS-15 is a reliable and valid screening tool for Major Depressive Disorder across different ages, gender, ethnicity, and chronic illness status in the community and social service setting. The 15 -item GDS was found to have sufficient internal consistency reliability $(\alpha=0.86)$ and retest reliability $(r=0.81)$ to support its use as a clinical instrument (Brown \& Schinka, 2005).

\section{Statistical Analysis}

The key findings of this analysis were improvements in muscle strengths and depression levels. Results have been recorded as standard deviations (SD) and mean $(\mathrm{m})$. The baseline demographic differences between groups were calculated with a one-way ANOVA and Chi-square test. The covariance analysis was carried out to assess the existence of confusing variables for all classes in baselines. The repeated measurement variance analyses (ANOVA) were used to determine whether time factor effects, group effects, and interaction between the two variables (group and time) were present for all groups. For all statistical studies, an alpha level was considered significant.

\section{RESULTS}

The final sample included 63 people (18 from PB, 23 from $P G$, and 22 from the CG group) with demographic characteristics tabulated in Table 1. Subjects' average age was $63.8(\mathrm{SD}=4.5$ years). Mean height, body weight and BMI were 1.55 $(\mathrm{SD}=0.12 \mathrm{~m}), 63.53 \mathrm{~kg}(\mathrm{SD}=10.87 \mathrm{~kg})$ and 26.42 $\mathrm{kg} / \mathrm{m}^{2}$, respectively $\left(\mathrm{SD}=4.52 \mathrm{~kg} / \mathrm{m}^{2}\right)$. There were no substantial demographic differences between groups except for the age variable where the significant difference was observed between $\mathrm{PB}$ and $\mathrm{CG} p<0.05$, refer to Table 1.

The repeated ANOVA tests on both the upper and lower limb strength were carried out. The study showed that none of the Levene's Tests was significant for both variables (all $p>0.05$ ), which is why it can be concluded that variances are homogeneous. In right upper limb, this study indicated that the lag period (baseline, week $12 \& 24$ ), $\left[\mathrm{F}(2.46,147.37)=61.11, p>0.05, \eta^{2}=0.51\right]$ has important effect on all three categories. There is also a significant time and group interaction difference $[\mathrm{F}(4.91,147.37)=71.79, p<0.05, \alpha=0.71]$ and intergroup influence, $\left[\mathrm{F}(2,60)=63.83, p<0.05, \eta^{2}=0.68\right]$. A significant has been shown in mean differences

Table 1. Demographic characteristic of the study sample

\begin{tabular}{|c|c|c|c|c|c|c|c|}
\hline \multirow{2}{*}{ Characteristic } & \multicolumn{2}{|c|}{ Group PB $(n=18)$} & \multicolumn{2}{|c|}{ Group PG $(n=23)$} & \multicolumn{2}{|c|}{ Group CG $(n=22)$} & \multirow{2}{*}{$\begin{array}{c}\mathrm{F} \text { test } \\
(P \text {-value })\end{array}$} \\
\hline & $n(\%)$ & $\mathrm{m} \pm \mathrm{SD}$ & $n(\%)$ & $\mathrm{m} \pm \mathrm{SD}$ & $n(\%)$ & $\mathrm{m} \pm \mathrm{SD}$ & \\
\hline Age (years) & & $66.1(6.21)$ & & $63.5(3.39)$ & & $62.3(3.07)$ & $F=3.943,0.025$ * \\
\hline Gender & & & & & & & $F=0.872, N S$ \\
\hline Male & $8(44.4)$ & & $15(65.2)$ & & $12(54.5)$ & & \\
\hline Female & $10(55.6)$ & & $8(38.4)$ & & $10(45.5)$ & & \\
\hline Bodyweight (kg) & & $59.82(3.33)$ & & $65.89(2.16)$ & & $64.19(1.66)$ & $F=1.642, N S$ \\
\hline Height (m) & & $1.53(0.03)$ & & $1.56(0.02)$ & & $1.57(0.02)$ & $F=0.659, N S$ \\
\hline $\mathrm{BMI}\left(\mathrm{kg} / \mathrm{m}^{2}\right)$ & & $25.83(1.58)$ & & $27.05(0.65)$ & & $26.27(0.76)$ & $F=0.370, N S$ \\
\hline Marital status & & & & & & & $\mathrm{F}=1.225, \mathrm{NS}$ \\
\hline Single & - & & $2(8.7)$ & & - & & \\
\hline Married & $17(94.4)$ & & $18(78.3)$ & & $19(86.4)$ & & \\
\hline Divorced & $1(5.6)$ & & $1(4.3)$ & & $3(13.6)$ & & \\
\hline Widowed & - & & $2(8.7)$ & & - & & \\
\hline Education level & & & & & & & $\mathrm{F}=40.630, p<0.05$ \\
\hline Never school & $4(22.2)$ & & $2(8.7)$ & & - & & \\
\hline Primary school & $9(50.0)$ & & $18(78.3)$ & & $14(63.6)$ & & \\
\hline Secondary school & $4(22.2)$ & & $3(13.0)$ & & $8(36.4)$ & & \\
\hline Others & $1(5.6)$ & & - & & - & & \\
\hline Working status & & & & & & & $\mathrm{F}=2.360, \mathrm{NS}$ \\
\hline Housewife & $5(27.8)$ & & $4(17.4)$ & & $5(22.7)$ & & \\
\hline Non-technical & $9(50.0)$ & & $6(26.1)$ & & $9(40.9)$ & & \\
\hline Work & $2(11.1)$ & & $2(8.7)$ & & $2(9.1)$ & & \\
\hline Technical work & $2(11.1)$ & & $5(21.7)$ & & $4(18.2)$ & & \\
\hline Retired & - & & $6(26.1)$ & & $2(9.1)$ & & \\
\hline Never work & - & & - & & - & & \\
\hline
\end{tabular}


$(p<0.05)$ between the groups of right upper limbs (PB \& $\mathrm{PG}=5.34 ; \mathrm{PB} \& \mathrm{PG}=8.65 ; \mathrm{PG} \& \mathrm{CG}=3.31$ ). Similarly in left upper limb strength, the analysis showed a significant difference in the time factor, $\left[\mathrm{F}(2.49,149.12)=35.33, p<0.05, \eta^{2}=0.37\right]$; time and group interaction, $[\mathrm{F}(4.97,149.12)=60.90, p<0.05$, $\left.\eta^{2}=0.67\right]$, and between group effect, $[\mathrm{F}(2,60)=45.48$, $\left.p<0.05, \eta^{2}=0.60\right]$. The post hoc test showed significant mean differences $(\mathrm{p}<0.05)$ for left upper limb strength among groups $(\mathrm{PB} \& \mathrm{PG}=5.06 ; \mathrm{PB} \&$ $\mathrm{PG}=8.22 ; \mathrm{PG} \& \mathrm{CG}=3.16$ ). In terms of the lower limb strength, the study revealed a substantial differences between the time factor of $[\mathrm{F}(2.55,152.94)$ $=95.81, p<0.05, \mu 2=0.70]$; time and group interaction, and between the effects of the group of time and group of time of $[\mathrm{F}(5.10,152.94)[\mathrm{F}(5.10,152.94)=31.25$, $p<0.05, \mu 2=0.51]$ and group of effects. The post-hoc test revealed considerable mean differences of the limb intensity $(p<0.05)$ between the different groups $(\mathrm{PB} \& \mathrm{PG}=4.44 ; \mathrm{PB} \& \mathrm{CG}=6.41 ; \mathrm{PG} \& \mathrm{CG}=1.97$ ). Refer Table 2.

A significant main effect was found on level of depression among the three groups $[\mathrm{F}(2,58)=33.49$, $\left.p<0.05, \eta^{2}=0.54\right]$ following the completion of the programs. Participants in $\mathrm{PB}$ (adjusted mean, $\mathrm{M}=$ 1.26 , standard error, $\mathrm{SE}=0.12)$ reported less depressed compared to EG (adjusted mean, $\mathrm{M}=2.04$, standard error, $\mathrm{SE}=0.10$ ) and $\mathrm{CG}$ (adjusted mean, $\mathrm{M}$ $=2.67$, standard error, $\mathrm{SE}=0.11$ ). Results of pairwise comparisons reported significant differences between $\mathrm{PB}$ and $\mathrm{PG}$ (mean difference $=0.78$, standard error, $\mathrm{SE}=0.15$ ), EPB and CG (mean difference $=1.40$, standard error, $\mathrm{SE}=0.17$ ), as well as $\mathrm{PG}$ and $\mathrm{CG}$ (mean difference $=0.62$, standard error, $\mathrm{SE}=0.16$ ) with all $p<0.05$. Refer Table 3 .

Table 2. Muscle strengths at baseline, $12^{\text {th, }}$ and $24^{\text {th }}$ weeks

\begin{tabular}{|c|c|c|c|c|c|}
\hline \multicolumn{6}{|c|}{ Right upper limb strength } \\
\hline \multirow[t]{2}{*}{ Time } & $\mathrm{PB}(n=18)$ & $\mathrm{PG}(n=23)$ & $\mathrm{CG}(n=22)$ & Sig. & $\begin{array}{c}\text { Mean difference } \\
\text { between-group } \\
\text { (F-test) }\end{array}$ \\
\hline & Mean (SD) & Mean (SD) & Mean (SD) & & \\
\hline Baseline & $11.39(2.06)$ & $10.83(1.99)$ & $11.36(2.61)$ & 0.65 & $\begin{array}{l}\text { PB-PG }=0.56 \\
\text { PB-CG }=0.03 \\
\text { PG-CG }=0.54\end{array}$ \\
\hline $12^{\text {th }}$ weeks & $20.28(3.80)$ & $15.43(2.45)$ & $10.73(2.88)$ & 0.00 * & $\begin{array}{l}\text { PB-PG }=4.84^{*} \\
\text { PB-CG }=9.55^{\star} \\
\text { PG-CG }=4.71^{*}\end{array}$ \\
\hline $24^{\text {th }}$ weeks & $22.56(3.33)$ & $11.04(2.55)$ & $8.68(1.91)$ & 0.00 * & $\begin{array}{l}\text { PB-PG }=11.51^{*} \\
\text { PB-CG }=13.87^{*} \\
\text { PG-CG }=2.36^{*}\end{array}$ \\
\hline \multicolumn{6}{|c|}{ Left upper limb strength } \\
\hline Baseline & $11.50(2.43)$ & $12.39(3.49)$ & $12.86(3.11)$ & 0.38 & $\begin{array}{l}\text { PB-PG }=0.89 \\
\text { PB-CG }=1.36 \\
\text { PG-CG }=0.47\end{array}$ \\
\hline $12^{\text {th }}$ weeks & $20.17(4.40)$ & $14.91(2.92)$ & $10.32(2.89)$ & 0.00 * & $\begin{array}{l}\text { PB-PG }=5.25^{\star} \\
\text { PB-CG }=9.85^{\star} \\
\text { PG-CG }=4.60^{*}\end{array}$ \\
\hline $24^{\text {th }}$ weeks & $21.44(3.76)$ & $10.83(2.81)$ & $8.36(1.99)$ & 0.00 * & $\begin{array}{l}\text { PB-PG }=10.62^{*} \\
\text { PB-CG }=13.08^{*} \\
\text { PG-CG }=2.46^{*}\end{array}$ \\
\hline \multicolumn{6}{|c|}{ Lower limb muscle strength } \\
\hline Baseline & $9.06(1.16)$ & $9.26(1.45)$ & $8.91(1.85)$ & 0.74 & $\begin{array}{l}\text { PB-PG }=0.21 \\
\text { PB-CG }=0.15 \\
\text { PG-CG }=0.35\end{array}$ \\
\hline $12^{\text {th }}$ weeks & $18.44(3.42)$ & $13.00(1.62)$ & $11.86(2.05)$ & 0.00 * & $\begin{array}{l}\text { PB-PG }=5.45^{*} \\
\text { PB-CG }=6.58^{*} \\
\text { PG-CG }=1.14\end{array}$ \\
\hline $24^{\text {th }}$ weeks & $19.50(2.81)$ & $11.35(2.12)$ & $9.68(2.08)$ & 0.00 * & $\begin{array}{l}\text { PB-PG }=8.15^{*} \\
\text { PB-CG }=9.82^{\star} \\
\text { PG-CG }=1.67\end{array}$ \\
\hline
\end{tabular}


Table 3. (A) Analysis of co-variance and (B) Pairwise comparisons of three interventions groups by the level of depression score

\begin{tabular}{lccccc}
\hline (A) Source & SS & Df & MS & F & P \\
\hline Depression score & 8.587 & 1 & 8.587 & 38.428 & $0.00^{*}$ \\
Groups & 14.965 & 2 & 7.483 & 33.485 & $0.00^{*}$ \\
Error & 12.961 & 58 & 0.223 & & \\
Total & 56.774 & 61 & & & \\
\hline (B) Variables/Group & Mean & Adjusted Mean & EBG & EG & CG \\
\hline Depression scores & & & & - & - \\
PB & 1.0588 & 1.257 & $.778^{*}$ & - & - \\
PG & 1.8986 & 2.036 & $1.401^{*}$ & $.622^{*}$ & - \\
CG & 2.9545 & 2.658 & & \\
\hline
\end{tabular}

Note: $p>0.05:$ Non-significant $=N S$.

\section{DISCUSSION}

The PB participants conducted the workout continuously, even though the structured monitoring of the exercise had ended. The increase in muscle strength may be attributed in part to the resistance training integrated into the multiple component exercise training because it can continuously stimulate the synthesis of muscle protein in the skeletal muscle (Yang \& Li, 2012). Besides, the resistance training was conducted at moderate to high intensity, twice a week, as indicated in the previous research (Chodzko-Zajko et al., 2009), and one meta-analysis (Peterson et al., 2012) could increase lean muscle mass and strength of elderly. Besides, the therapeutic program may have helped participants in the $\mathrm{PB}$ to maintain their exercise commitment and self-esteem. This is partly because they received a talk about the value of exercise within the behavioral program, determined their target setting, and received constructive self-talk. In the present research, the investigator found out, despite aging circumstances, a behavioral program would successfully improve sensitivity and change attitudes to exercise participation.

The researchers claimed that the implementation of a strengthening management approach to the behavioral program for PB participants had gained constructive incentives and are a role model for others to change their behavior. They played, for example, "UniFitt Garden," enabling the members to grow their gardens with their companions or groups. When participants reach their target in the garden project, which is 10,000 steps a day, the garden with different flowers will become nicer and enjoyable. This activity provides a fun and promotes the social support of the wives and friends of the elderly (Henderson \& Ainsworth, 2003).
Unlike the PG and CG participants, they were not sensible and encouraged enough to practice at home. They may think that exercise is another program or practice that is negative to their everyday routine. The side effects of workouts such as fatigue, sweat, and muscle soreness can also be due to poor motivation (Williams et al., 2002). In addition, sudden termination of exercises in the PG may lead to a loss of teammates, group results, and instructors' enthusiasm as these aspects are seen as obstacles to continue participatory action (Guerin et al., 2008). Contrasting to $\mathrm{PB}$, participants in PG and CG do not provide motivational service, social support, or behavioral curriculum. These additional and external factors affect whether a person can continue or stop practicing active routine (Cohen-Mansfield et al., 2003; Schutzer \& Graves, 2004). The individual physical effects of exercise will take several weeks to be identified. Therefore, after six weeks of detraining, their muscle strength will steadily decrease (Toraman \& Ayceman, 2005).

Similarly, the participants in CG displayed the lowest efficiency in all muscle functions. The decline in muscle strength with aging is also correlated with both physical inactiveness and a decrease in different skeletal muscle functions because of natural aging processes. These physiological changes include decreased contractility (Faulkner et al., 2007), musculature atrophy (Suetta et al., 2013), increased occurrence of various neuromuscular conditions (Sharma \& Goodwin, 2006). Sedentary individuals with a lack of physical activities may be at risk of physical disabilities due to generalized muscle weakness.

In the three groups, the lowest degree of depression was found in PB compared with the other groups following the conclusion of the research. The adaptation in PB might be influenced by the 
behavioral techniques applied in this research, such as the "motivational interview". Participants can also feel relaxed since it is a customer-focused approach that is not only based on the teaching of new mental skills but also equipped to improve their self-esteem. Training programs have strengthened optimistic moods in aging stable communities, as previous studies have shown clinically that exercise helps to avoid or minimize depressive severity whether as a complementary or alternative to depression (Sjösten \& Kivelä, 2006; Taekema et al., 2010).

Research has shown that exercise training can lead to substantial dendritic remodeling (Yau et al., 2011) and can facilitate the development of adult hippocampal neurogenesis (Folstein, 2007; Helmich et al., 2010) in the brain. Exercises have improved mechanism happens as the synthesis of brain neurons in the brain rises approximately 2 to 3 fold in the hippocampal region. (Craft \& Perna, 2004), $\beta$ - endorphin levels (Craft \& Perna, 2004) and endothelial vascular growth factor (VEGF) (Ernst et al., 2006). The mechanism helps to increase the growth of $\beta$ - Endorphins and extend their survival by stimulating VEGF and BDNF of new neurons in the dentate gyrus. 5-HT increases the mechanism of cell proliferation and improves neurogenesis (Craft \& Perna, 2004). As early as 3 days, participants in $\mathrm{PB}$ and $\mathrm{PG}$ who have been trained may experience neurogenesis after the beginning of the training. When this occurs, the depression level may be lowered or sustained.

The increase in the PB standard may also be clarified because of the length of training. Those in the PB community may have extended their workout time because the therapeutic modification has improved them. According to Manos in his study, the Behavioural Activation Model of depression included strengthening, mood, actions, and depression in the relationship of the four main components that have a significant effect on one's behavior (Manos et al., 2010).

During the behavioral lessons, deep breathing exercises have been shown to alleviate depressive symptoms by increasing heart rate variability and parasympathetic response (Chung et al., 2010). As each of the participants in PMR played alternating muscle tension and relaxation involving major muscles such as neck (trapezius, sternocleidomastoids), shoulder (deltoids), chest (pectoral major), legs (hamstrings, quadriceps), wrist $\&$ hand (flexors, extender). During PMR, the participants had to focus their mind on the muscle group with closed eyes for $10 \mathrm{~s}$ (stress) and release it for $20 \mathrm{~s}$, before proceeding with the next muscle group. The difference between feelings of tension and relaxation may require great attention, thus making them beneficial in handling positive sense, and therefore can lead to lower levels of depression.

\section{CONCLUSION}

There are certain limitations on the generalizability of these effects. For example, those with serious and major depressive diseases do not apply. The elderly with serious depression may need antidepressant medication and a personal approach. Moreover, the potential impact of attention and support by therapeutic alliances among PB subjects may occur. These differences need to be highlighted, and subsequent research should rely on handling the same exposure and regulated setting. Based on this study's hypothesis, it can now be stated that 6-week training in conjunction with a 5 -week behavioral program can have beneficial effects on muscle strengths and mental health in the elderly.

\section{ACKNOWLEDGEMENTS}

We want to thank all the participants for their full cooperation throughout this study and Universiti Teknologi Mara for the facilities. The authors report no conflicts of interest.

\section{REFERENCES}

Atkins, J.M., Matthews, O.A., Blomqvist, C.G. \& Mullins, C.B. 1976. Incidence of arrhythmias induced by isometric and dynamic exercise. British Heart Journal, 38: 465-571.

Azliyana, A. \& Maria, J. 2016. Effects of a behavioral and exercise program on depression and quality of life in community-dwelling older adults. Journal of Gerontological Nursing, 42: 45-54.

Ballmaier, M., Sowell, E.R., Thompson, P.M., Kumar, A., Narr, K.L., Lavretsky, H., Welcome, S.E., DeLuca, H. \& Toga, A.W. 2004. Mapping brain size and cortical gray matter changes in elderly depression. Biological Psychiatry, 55: 382-389.

Beekman, A.T.F., Copeland, J.R.M. \& Prince, M.J. 1999. Review of community prevalence of depression in later life. British Journal of Psychiatry, 174: 307- 311.

Brown, L.M. \& Schinka, J.A. 2005. Development of initial validation of a 15 -item informant version of the Geriatric Depression Scale. International Journal of Geriatric Psychiatry, 20: 911-918.

Chodzko-Zajko, W.J., Proctor, D.N., Fiatarone Singh, M.A., Minson, C.T., Nigg, C.R., Salem, G.J. \& Skinner, J.S. 2009. Exercise and physical activity for older adults. Medicine \& Science in Sports \& Exercise, 41 (7): 1510-1530.

Cohen-Mansfield, J., Marx, M.S. \& Guralnik, J.M. 2003. Motivators and barriers to exercise in an older community-dwelling population. Journal of Aging and Physical Activity, 11: 242-253. 
Craft, L.L. \& Perna, F.M. 2004. The benefits of exercise for the clinically depressed. The Primary Care Companion to The Journal of Clinical Psychiatry, 6(3): 104-111.

Donaghy, M.E. 2007. Exercise can seriously improve your mental health: Fact or fiction? Advances in Physiotherapy, 9(2): 76-88.

Duman, R.S. 1997. A molecular and cellular theory of depression. Archives of General Psychiatry, 54(7): 597.

Ernst, C., Olson, A.K., Pinel, J.P.J., Lam, R.W. \& Christie, B.R. 2006. Antidepressant effects of exercise: Evidence for an adult-neurogenesis hypothesis? Journal of Psychiatry and Neuroscience, 31: 84-92.

Faulkner, J.A., Larkin, L.M., Claflin, D.R. \& Brooks, S.V. 2007. Age-related changes in the structure and function of skeletal muscles. Clinical and Experimental Pharmacology and Physiology, 34 (11): 1091-1096.

Fitzgerald, P.B., Laird, A.R., Maller, J. \& Daskalakis, Z.J. 2008. A meta-analytic study of changes in brain activation in depression. Human Brain Mapping, 29: 683-695.

Folstein, M. 2007. The homocysteine hypothesis of depression. American Journal of Psychiatry, 164: 861.

Guerin, M., Mackintosh, S. \& Fryer, C. 2008. Exercise class participation among residents in low-level residential aged care could be enhanced: A qualitative study. Australian Journal of Physiotherapy, 54: 111-117.

Helmich, I., Latini, A., Sigwalt, A., Carta, M.G., Machado, S., Velasques, B., Ribeiro, P. \& Budde, H. 2010. Neurobiological alterations induced by exercise and their impact on depressive disorders. Clinical Practice and Epidemiology in Mental Health: CP \& EMH, 6: 115-125.

Henderson, K.A. \& Ainsworth, B.E. 2003. A synthesis of perceptions about physical activity among older African American and American Indian women. American Journal of Public Health, 93 (2): 313-317.

Ketcham, C.J. \& Stelmach, G.E. 2004. Movement control in the older adult. Technology for adaptive aging [WWW Document]. URL https://www.ncbi.nlm.nih.gov/sites/books/ NBK97342/\%0A https://www.ncbi.nlm.nih.gov/ books/NBK97342/\#top (accessed mm.dd.yyyy)

Kørner, A., Lauritzen, L., Abelskov, K., Gulmann, N., Marie Brodersen, A., Wedervang- Jensen, T. \& Marie Kjeldgaard, K. 2006. The geriatric depression scale and the cornell scale for depression in dementia. A validity study. Nordic Journal of Psychiatry, 60: 360-364.
Kraemer, W., Adams, K., Cafarelli, E., Dudley, G.A., Dooly, C., Feigenbaum, M.S., Fleck, S.J., Franklin, B., Fry, A.C., Hoffman, J.R., Newton, R.U., Potteiger, J., Stone, M.H., Ratamess, N.A., Triplett-McBride, T. \& American College of Sports Medicine. 2002. Progression models in resistance training for healthy adults. Medicine and Science in Sports and Exercise, 34(2): 364380.

Majdi, M.R., Mobarhan, M.G., Salek, M., Taghi, M. \& Mokhber, N. 2011. Prevalence of depression in an elderly population: A population-based study in Iran. Iranian Journal of Psychiatry and Behavioral Sciences, 5 (1): 17-21.

Manor, B., Topp, R. \& Page, P. 2006. Validity and reliability of measurements of elbow flexion strength obtained from older adults using elastic bands. Journal of Geriatric Physical Therapy, 29: 16-19.

Manos, R.C., Kanter, J.W. \& Busch, A.M. 2010. A critical review of assessment strategies to measure the behavioral activation model of depression. Clinical Psychology Review, 30: 547-561.

Milanović, Z., Pantelić, S., Trajković, N., Sporiš, G., Kostić, R. \& James, N. 2013. Age- related decrease in physical activity and functional fitness among elderly men and women. Clinical Interventions in Aging, 8: 549-556.

Mobasheri, A. 2012. Proteomic profiling and its applications to muscle aging and sarcopenia. Frontiers in Physiology, 2: 105.

Nyunt, M.S.Z., Fones, C., Niti, M. \& Ng, T.-P. 2009. Criterion-based validity and reliability of the Geriatric Depression Screening Scale (GDS-15) in a large validation sample of community-living Asian older adults. Aging \& Mental Health, 13(3): 376-82.

Peterson, C.M., Johannsen, D.L. \& Ravussin, E. 2012. Skeletal muscle mitochondria and aging: A review. Journal of Aging Research, 2012: 1-20.

Rikli, R.E. \& Jones, C.J. 2013. Development and validation of criterion-referenced clinically relevant fitness standards for maintaining physical independence in later years. Gerontologist, 53: 255-267.

Salguero, A., Martínez-García, R., Molinero, O. \& Márquez, S. 2011. Physical activity, quality of life and symptoms of depression in communitydwelling and institutionalized older adults. Archives of Gerontology and Geriatrics, 53: 152-157.

Schutzer, K.A. \& Graves, B.S. 2004. Barriers and motivations to exercise in older adults. Preventive Medicine, 39: 1056-1061. 
Sharma, G. \& Goodwin, J. 2006. Effect of aging on respiratory system physiology and immunology. Clinical Interventions in Aging, 1(3): 253-260.

Sjösten, N. \& Kivelä, S.L. 2006. The effects of physical exercise on depressive symptoms among the aged: A systematic review. International Journal of Geriatric Psychiatry, 21: 410-418.

Smith, G.S. 2008. Neurochemical brain imaging of treatment response in geriatric depression. Dialogues in Clinical Neuroscience, 10: 482486.

Suetta, C., Frandsen, U., Mackey, A.L., Jensen, L., Hvid, L.G., Bayer, M.L., Petersson, S.J., Schrøder, H.D., Andersen, J.L., Aagaard, P., Schjerling, P., Kjaer, M. 2013. Ageing is associated with diminished muscle re-growth and myogenic precursor cell expansion early after immobilityinduced atrophy in human skeletal muscle. Journal of Physiology, 591: 3789-3804.

Taekema, D.G., Gussekloo, J., Maier, A.B., Westendorp, R.G.J. \& de Craen, A.J.M. 2010. Handgrip strength as a predictor of functional, psychological, and social health. A prospective population-based study among the oldest old. Age and Ageing, 39(3): 331-337.

The National Institute for Health and Care Excellence. 2009. Depression. The treatment and management of depression in adults. NICE Guidelines (CG90), 1-592 [WWW Document]. URL http:// www.ncbi.nlm.nih.gov/books/NBK55364/ (accessed mm.dd.yyyy)

Toraman, N.F. \& Ayceman, N. 2005. Effects of six weeks of detraining on retention of functional fitness of old people after nine weeks of multicomponent training. British Journal of Sports Medicine, 39: 565-568.
Tsopelas, C., Stewart, R., Savva, G.M., Brayne, C., Ince, P., Thomas, A. \& Matthews, F.E. 2011. Neuropathological correlates of late-life depression in older people. British Journal of Psychiatry, 198: 109-114.

Vieira, D.C., Tibana, R.A., Tajra, V., Nascimento, D., de Farias, D.L., Silva, A., Teixeira, T.G., Fonseca, R.M., de Oliveira, R.J., Mendes, F.A., Martins, W.R., Funghetto, S.S., Karnikowski, M.G., Navalta, J.W. \& Prestes, J. 2013. Decreased functional capacity and muscle strength in elderly women with metabolic syndrome. Clinical Interventions in Aging, 8: 1377-1386.

Wada, T., Ishine, M., Sakagami, T., Kita, T., Okumiya, K., Mizuno, K., Rambo, T.A. \& Matsubayashi, K. 2005. Depression, activities of daily living, and quality of life of community-dwelling elderly in three Asian countries: Indonesia, Vietnam, and Japan. Archives of Gerontology and Geriatrics, 41: 271-280.

Williams, G.N., Higgins, M.J. \& Michael, D. 2002. Aging skeletal muscle: Physiologic changes and the effects. Physical Therapy, 82(1): 62-68.

Wilson, N., Sambrook, P., Hilmer, S., March, L., Cameron, I., Lord, S. \& Mason, R. 2011. Physical functioning measures and risk of falling in older people living in residential aged care facilities. Therapeutic Advances in Musculoskeletal Disease, 3 (1): 9-15.

Yang, S. \& Li, Q. 2012. Inertial sensor-based methods in walking speed estimation: A systematic review. Sensors, 12(5): 6102-6116.

Yau, S.-Y., Lau, B.W.-M., Tong, J.-B., Wong, R., Ching, Y.-P., Qiu, G., Tang, S.W., Lee, T.M. \& So, K.-F. 2011. Hippocampal neurogenesis and dendritic plasticity support running-improved spatial learning and depression-like behaviour in stressed rats. PLOS ONE, 6: E24263. 